\title{
Heat Transfer Performance of R-1234ze(E) with the Effect of High-Viscosity POE Oil on Enhanced GEWA-B5H Tube
}

\author{
Abhishek Kumar ${ }^{1}{ }^{\mathbb{D}}$, Miao-Ru Chen ${ }^{2}$, Jung-Hsien Wu ${ }^{2}$, Kuo-Shu Hung ${ }^{2}$, Li-Kang Su ${ }^{2}$ and Chi-Chuan Wang ${ }^{1, *}$ \\ 1 Department of Mechanical Engineering, National Yang-Ming Chiao Tung University, Hsinchu 300, Taiwan; \\ abhishek.en06@nycu.edu.tw \\ 2 Green Energy \& Environment Research Laboratories, Industrial Technology Research Institute, \\ Hsinchu 310, Taiwan; MiaoRuChen@itri.org.tw (M.-R.C.); JH.Wu@itri.org.tw (J.-H.W.); \\ kshung@itri.org.tw (K.-S.H.); likangsu@itri.org.tw (L.-K.S.) \\ * Correspondence: ccwang@nycu.edu.tw; Tel.: +886-3-5712121 (ext. 55105); Fax: +886-3-5720634
}

Citation: Kumar, A.; Chen, M.-R.; Wu, J.-H.; Hung, K.-S.; Su, L.-K.; Wang, C.-C. Heat Transfer

Performance of R-1234ze(E) with the Effect of High-Viscosity POE Oil on Enhanced GEWA-B5H Tube. Processes 2021, 9, 2285. https://doi.org/ $10.3390 /$ pr9122285

Academic Editor: Weizhong Dai

Received: 23 November 2021

Accepted: 18 December 2021

Published: 20 December 2021

Publisher's Note: MDPI stays neutral with regard to jurisdictional claims in published maps and institutional affiliations.

Copyright: (c) 2021 by the authors. Licensee MDPI, Basel, Switzerland. This article is an open access article distributed under the terms and conditions of the Creative Commons Attribution (CC BY) license (https:// creativecommons.org/licenses/by/ $4.0 /)$.

\begin{abstract}
In this study, the heat transfer performance of high-viscosity polyol ester (POE) oil POEA220 (220 cSt) with low-GWP (global warming potential) refrigerant R-1234ze(E) on enhanced GEWA$\mathrm{B} 5 \mathrm{H}$ tube was investigated at saturation temperatures of $10^{\circ} \mathrm{C}, 0^{\circ} \mathrm{C}$, and $-6^{\circ} \mathrm{C}$. The mass fraction of oil varied from $0.25 \%$ to $10 \%$, and all the nucleate pool boiling data were measured at heat fluxes ranging from $10 \mathrm{~kW} / \mathrm{m}^{2}$ to $90 \mathrm{~kW} / \mathrm{m}^{2}$. The experimental results showed that the heat transfer performance of the R-1234ze(E)/POEA-220 mixtures were superior to the R-1234ze(E)/POEA-68 mixtures. At saturation temperatures of $0{ }^{\circ} \mathrm{C}$ and $-6{ }^{\circ} \mathrm{C}$, even a $10 \%$ mass fraction of the POEA-220 oil showed an enhancement in the HTC (heat transfer coefficient) compared to the pure refrigerant in the moderate heat flux range. On the other hand, for the R-1234ze(E)/POEA-68 mixtures, a $5 \%$ mass fraction of oil showed no enhancement in the HTC compared to pure refrigerant at the same saturation temperature. Moreover, at low saturation temperatures $\left(0{ }^{\circ} \mathrm{C}\right.$ and $\left.-6{ }^{\circ} \mathrm{C}\right)$, the enhancement in the HTC decreased with increasing mass fraction of low-viscosity oil POEA-68, whereas high-viscosity oil POEA-220 showed the highest enhancement in the HTC for a 5\% mass fraction of oil at $-6{ }^{\circ} \mathrm{C}$ saturation temperature compared to the pure refrigerant. The results indicate that for nucleate boiling, the effect of oil viscosity on heat transfer performance is negligible if it contains comparatively high thermal conductivity and low surface tension. In addition, the effect of surface aging on heat transfer performance for the GEAW-B5H tube with pure refrigerant was also reported.
\end{abstract}

Keywords: low GWP; R-1234ze(E); high-viscosity POE oil; nucleate boiling; HTC; surface aging

\section{Introduction}

Specific refrigerant-oil pairs are required for the efficient operation of the compressor and refrigeration system. The oil miscibility, lubricity, solubility, and viscosity are essential parameters to characterize the suitability when mixing with refrigerant. Moreover, to limit a rise in global warming below $1.5^{\circ} \mathrm{C}$ and tackle climate change issues, environmental protection agencies (F-gas regulation, Montreal protocol, Peris climate agreement-2016, and, most recently COP26-2021) have scheduled to phase down all the high-GWP (global warming potential) refrigerants by the end of this decade (2030). As a result, an era of third- generation HFC (hydrofluorocarbon) refrigerants face an uncertain future due to their high GWP. In the past decades, several low-GWP refrigerants have been developed by several manufactures and recognized by the ASHRAE (American Society of Heating Refrigerating and Air-Conditioning Engineers), which are termed as fourth-generation HFO (hydrofluroolefin) refrigerants. Among them, R-1234ze(E) is one of the ultra-low-GWP refrigerant $(\mathrm{GWP}<1)$ alternatives to $\mathrm{R}-134 \mathrm{a}$ that has been tested by several researchers in the past decades, and detailed summaries are available in References [1-3]. However, 
its compatibility with suitable lubricant oil in terms of heat transfer performance has been scarcely described the literature [4-6].

In general, high-viscosity oil is preferred and recommended by compressor manufacture for high-temperature applications to ensure adequate lubricity of the compressor parts. However, using high-viscosity oil creates some challenges for the design engineer because the oil separator in the refrigeration system is unable to secure a $100 \%$ oil return to the compressor. Eventually, it mixes with pure refrigerant and accumulates on the evaporator tubes (smooth/enhanced), thereby affecting the system performance. The HTC of an enhanced surface is very sensitive to lubricant oil compared to the smooth surface, and even a small mass content of oil deteriorates the HTC.

Jensen and Jackmen [7] tested the R-113 oil mixture outside a stainless-steel tube and concluded that increasing the oil concentration and viscosity decreased the heat transfer coefficient. In contrast, Morgan et al. [8] sho that the highest viscosity has the highest heat transfer coefficient. Similar results were also reported by Kedzierski [9], who stated that "lubricants with larger viscosities have higher boiling heat transfer coefficients because the thermal boundary layer is thicker".

Spindler and Hahne [10] investigated the effect of polyol ester SE55 oil ( $\omega=0$ to 5\%) with R-134a on the GEWA-B surface. They reported that the HTC of the R-134a/SE-55 mixtures was comparatively lower than that of pure refrigerant. Even a low mass fraction of oil impaired the HTC between $40 \%$ and $20 \%$. However, the authors did not perform experiments for the high viscosity SE170 oil on the enhanced tube because the drastic degradation in the HTC was already observed for SE-55.

The influence of R-507/POE-oil mixtures on the enhanced tube was reported by Mohrlok et al. [11] considering the influence of saturation temperature (from $-28.6{ }^{\circ} \mathrm{C}$ to $20.1^{\circ} \mathrm{C}$ ). They showed that for $\omega=5 \%$, the HTC decreased when the saturation temperature was increased from $0.2{ }^{\circ} \mathrm{C}$ to $20.1{ }^{\circ} \mathrm{C}$. The lowest HTC was observed for $\omega=3 \%$ at a saturation temperature of $20.1{ }^{\circ} \mathrm{C}$, while the further addition of oil to $\omega=10 \%$ impaired the HTC by $5 \%$ at a saturation temperature of $20.1{ }^{\circ} \mathrm{C}$. Similar results were reported by Kim and Kim [12] subject to the effect of saturation temperature on HTC. A detailed summary regarding the influence mixture of refrigerant and oil on the GEWA tubes has been described by the authors of [13].

In summary, the above mentioned literature has revealed that the addition of lubricant oil to the pure refrigerant considerably alters the heat transfer performance of evaporator tubes (smooth/enhanced). For example, on the enhanced tube, the oil accumulates in the cavity/microchannel, resulting in an increase of the thermal resistance and impairing the HTC $[14,15]$. However, either the enhancement or degradation in HTC strongly depends on the specific pair of refrigerant oil mixtures and mass fraction of the oil $(\omega)$, as well as experimental conditions, such as the saturation temperature, evaporator pressure, heat flux, surface geometry, and type of oil (Mineral oil, Alkylbenzene, Polyalphaolefins, Polyalkylene glycol, Polyvinyl ether, and Polyol ester).

Most recently, Kumar and Wang [13] experimentally investigated the influence of a low-viscosity POEA-68 oil ( $\omega=0.28$ to $5 \%$ ) on the GEWA-B5H tube with R-134a and $\mathrm{R}-1234 z e(E)$ at saturation temperatures of $10{ }^{\circ} \mathrm{C}, 0{ }^{\circ} \mathrm{C}$, and $-6{ }^{\circ} \mathrm{C}$, respectively. They reported that the R-1234ze(E)/POEA-68 oil mixture yielded an enhancement in the HTC compared to the pure refrigerant for the lowest mass fraction of the oil $(0.28$ and $0.5 \%)$ at a saturation temperature of $10^{\circ} \mathrm{C}$. Whereas R-134a/POEA-68 oil mixture had a negligible enhancement in the HTC compared to the pure refrigerant for the same mass fraction of oil at the same saturation temperature. However, with the further decrease in saturation temperature (i.e., $0^{\circ} \mathrm{C}$ and $-6^{\circ} \mathrm{C}$ ), the enhancement in the HTC became more pronounced for the R-1234ze(E)/POEA-68 oil mixture. Their results indicate that the compatibility of polyol ester oil (in terms of miscibility, solubility, and heat transfer performance) with low-GWP refrigerant R-1234ze(E) is superior to R-134a when the saturation temperature decreases from $10{ }^{\circ} \mathrm{C}$ to $-6{ }^{\circ} \mathrm{C}$ due to the absolute pressure difference between $\mathrm{R}-134 \mathrm{a}$ and 
R-1234ze(E) at the same saturation temperature, which considerably affects the bubble dynamics and boiling mechanism.

In this study, based on the previous heat transfer performance results of R-1234ze(E)/ POEA-68 mixtures on the GEWA-B5H tube [13], further tests conducted with high-viscosity polyol ester oil POEA-220. The maximum mass fraction of oil was increased from $5 \%$ to $10 \%$, and the heat transfer performances of seven refrigerant-oil mixtures (R-1234ze(E)/POEA220) were also tested on the same tube at the saturation temperatures of $10^{\circ} \mathrm{C}, 0{ }^{\circ} \mathrm{C}$, and $-6{ }^{\circ} \mathrm{C}$. The mass fraction of oil varied from $0.25 \%$ to $10 \%$, and all tests were conducted in heat fluxes ranging from $10 \mathrm{~kW} / \mathrm{m}^{2}$ to $90 \mathrm{~kW} / \mathrm{m}^{2}$. Moreover, the present experimental results of the R-1234ze(E)/POEA-220 mixtures were compared with previous results of the R-1234ze(E)/POEA-68 mixtures on the GEWA-B5H tube. In addition, the effect of surface aging on HTC was also discussed.

\section{Experimental Apparatus and Methods}

\subsection{Experimental Apparatus}

The same experimental system was used in the present study as described by Kumar and Wang [13] and shown in Figure 1. The experimental system consisted of an evaporator vessel, condenser vessel, test section, thermostat tank, power supply unit, data logger unit (MX-100), T-type thermocouples, absolute pressure transducer, gauge pressure transducer, gear pump, digital weight balance, vacuum pump (not depicted in Figure 1), high-speed camera, LED light, safety valve, personal computer, and relevant auxiliary equipment. A detailed dimension of the evaporator vessel and condenser vessel was described by the authors of [16]. The evaporator vessel had side-glass windows of $72 \mathrm{~mm}$ (for the high-speed camera: spatial resolution $1280 \times 1020-320 \times 240$ pixels) and $42 \mathrm{~mm}$ (for lighting).

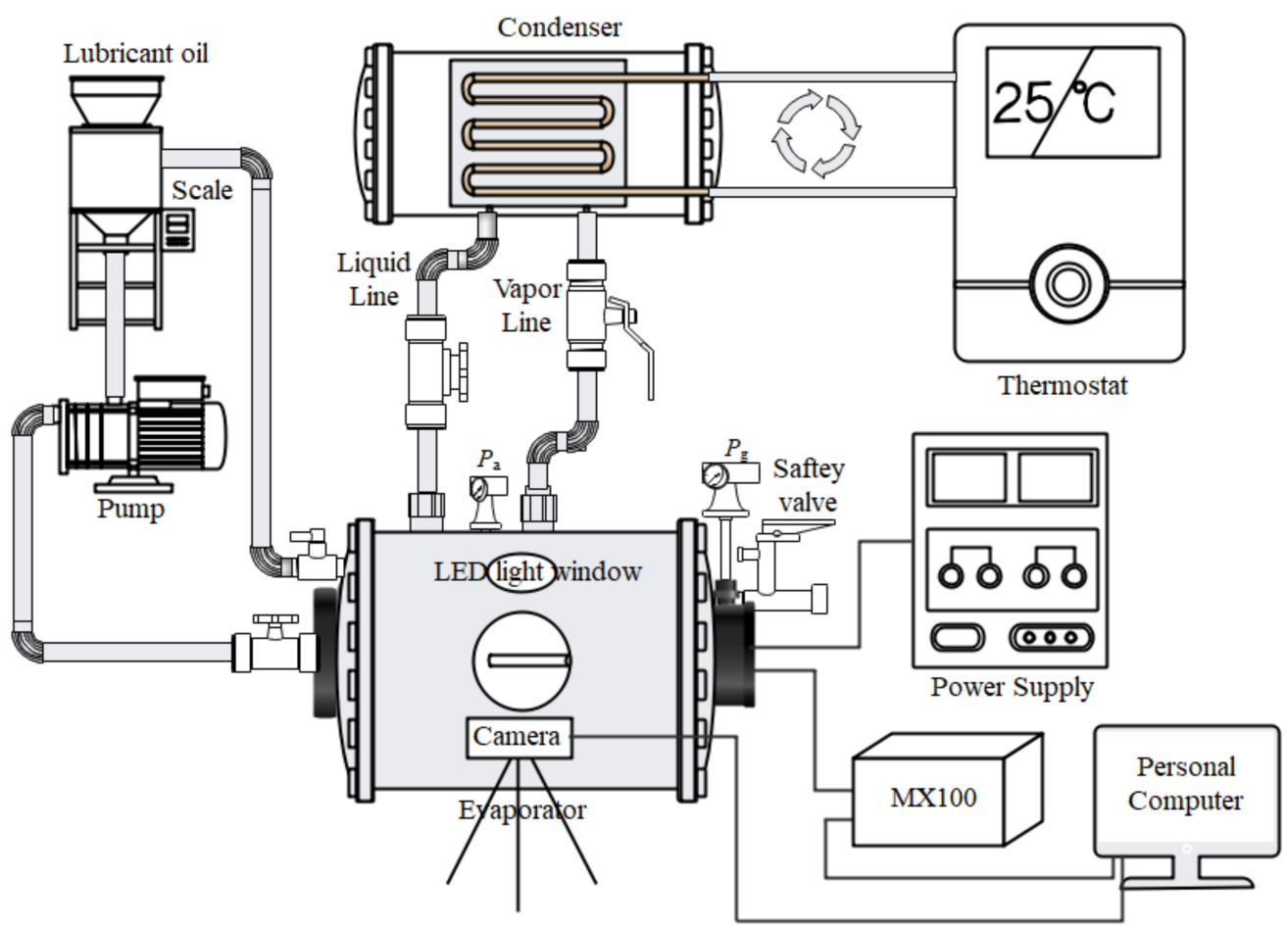

Figure 1. Schematic diagram of the experimental apparatus.

The vapor generated from the test surface in the evaporator vessel was condensed at the condenser vessel by the circulating of ethyl alcohol through the plate-fin-tube heat exchanger with the help of a low-temperature bath to complete the refrigerant circulation.

A Yokogawa (FP101A-D21) absolute pressure transducer was used to measure the saturation temperature of the liquid. To minimize the heat loss with the environment, all 
the circulating pipes, evaporator vessels, and condenser vessels were thermally insulated by a thick $(45 \mathrm{~mm})$ cellular rubber sheet.

\subsection{Test Section}

The test section used in the present study was briefly described by the authors of [13] and is depicted in Figure 2. To install thermocouples, an additional smooth copper tube with a nearly equivalent diameter of the inner surface of the GEWA-B5H tube was horizontally welded on the copper block. Four thermocouple holes that were 90 degrees apart, $1.1 \mathrm{~mm}$ in diameter, and $125 \mathrm{~mm}$ long were drilled along the outer circumference of the smooth tube. Indium foil was used to fill the groove to minimize contact resistance. A $1 \mathrm{~kW}$ cylindrical cartridge heater was installed inside the smooth copper tube to supply the heat for the test surface.

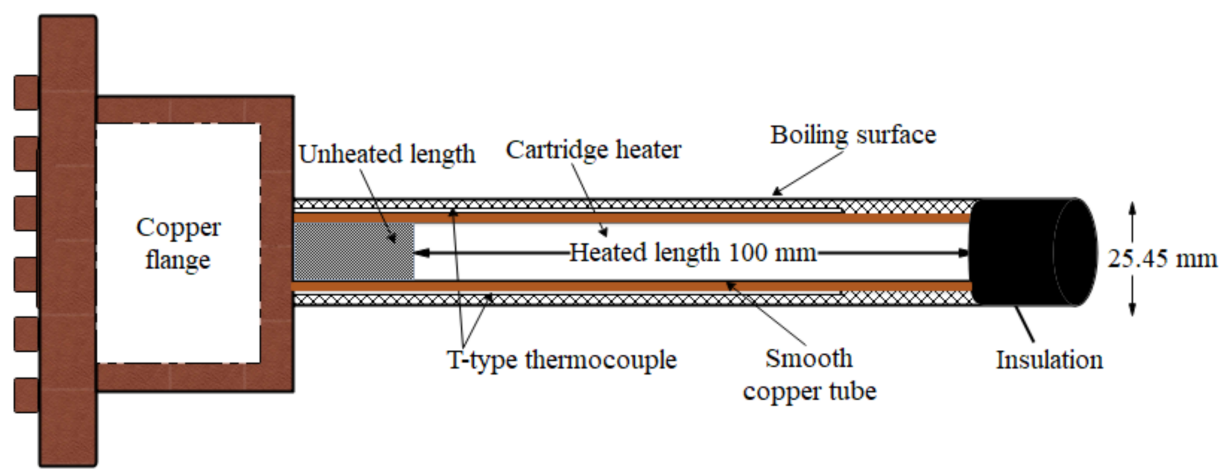

Figure 2. Schematic diagram of the test section assembly.

\subsection{Data Reduction and Associated Uncertainty}

The mass fraction $(\omega)$ of the POEA-220 oil added to pure refrigerant was estimated by Equation (1):

$$
\omega=\frac{m_{l}}{m_{r}+m_{l}} \times 100 \%
$$

where, $m_{\mathrm{l}}$ is the mass of the oil, and $m_{\mathrm{r}}$ is mass of the pure refrigerant. The uncertainty associated with the mass fraction of oil was calculated by $(\Delta \omega / \omega) \times 100 \%$ and it was in the range from 1.27 to $0.5 \%$ for $\omega=0.25-10 \%$.

Heat flux is calculated by Equation (2):

$$
q^{\prime \prime}=\frac{Q}{A_{o}}=\frac{V I}{A_{o}}
$$

where $q^{\prime \prime}$ is the heat flux, $Q$ is the power input, $V$ is the voltage, $I$ is current, and $A_{\mathrm{o}}$ is the outside surface area of the tube. The HTC of the pure refrigerant $\left(h_{0}\right)$ and refrigerant-oil mixtures $\left(h_{\mathrm{m}}\right)$ was calculated using Equation (3):

$$
h_{0 / \mathrm{m}}=\frac{q^{\prime \prime}}{\left(T_{w}-T_{\mathrm{sat}}\right)}
$$

where, $T_{\mathrm{W}}$ is the wall temperature, and $T_{\text {sat }}$ is the saturation temperature of the working liquid (i.e., pure refrigerant/refrigerant-oil mixture). The wall temperature $\left(T_{\mathrm{W}}\right)$ was estimated by Fourier's law using Equation (4):

$$
T_{\mathrm{w}}=T_{\mathrm{avg}}-Q \times \frac{\ln \left(d_{\mathrm{o}} / d_{\mathrm{i}}\right)}{2 \pi k_{\mathrm{c}} l}
$$

where $T_{\text {avg }}$ is average temperature of the four T-type thermocouples, $d_{\mathrm{O}}$ is the outer tube diameter, $d_{\mathrm{i}}$ is the diameter of the thermocouple position, $k_{\mathrm{c}}$ is the thermal conductivity of the copper, and $l$ is the heated length of the test tube. 
The error associated with the HTC and heat flux for the refrigerant and refrigerant oil mixtures has been briefly reported by the authors of $[13,16,17]$. The smallest wall superheats $\left(\Delta T_{\mathrm{W}}\right)$ for the pure refrigerant and refrigerant-oil mixture at the heat flux of $10 \mathrm{~kW} / \mathrm{m}^{2}$ was $0.76^{\circ} \mathrm{C}$ and $0.88{ }^{\circ} \mathrm{C}$ respectively. Thus, uncertainty in the wall superheat $\left(\delta \Delta T_{\mathrm{w}} / \Delta T_{\mathrm{w}}\right) \times$ $100 \%$ was $13.15 \%$ and $11.36 \%$ for the refrigerant and refrigerant-oil mixtures, respectively. The relative error in the heat flux was estimated by Equation (5):

$$
\frac{\delta q^{\prime \prime}}{q^{\prime \prime}}=\sqrt{\left(\frac{\delta Q}{Q}\right)^{2}+\left(\frac{\delta d_{\mathrm{o}}}{d_{\mathrm{o}}}\right)^{2}+\left(\frac{\delta l}{l}\right)^{2}}
$$

The error calculated in the heat flux from $10 \mathrm{~kW} / \mathrm{m}^{2}$ to $90 \mathrm{~kW} / \mathrm{m}^{2}$ using Equation (5) was between 3.75 and $0.53 \%$. Hence, the maximum error associated with HTC for the pure refrigerant and mixtures was calculated using Equation (6):

$$
\frac{\Delta h_{0 / \mathrm{m}}}{h_{0 / \mathrm{m}}}=\sqrt{\left(\frac{\delta q^{\prime \prime}}{q^{\prime \prime}}\right)^{2}+\left(\frac{\delta \Delta T_{\mathrm{w}}}{\Delta T_{\mathrm{w}}}\right)^{2}}
$$

The uncertainty in HTC for the refrigerant at a heat flux between $10 \mathrm{~kW} / \mathrm{m}^{2}$ and $90 \mathrm{~kW} / \mathrm{m}^{2}$ was between 13.67 and $2.96 \%$, whereas for mixtures error in the HTC at a heat flux between $10 \mathrm{~kW} / \mathrm{m}^{2}$ and $90 \mathrm{~kW} / \mathrm{m}^{2}$ was between 11.95 and $3.14 \%$.

\subsection{Test Procedure}

First, the experimental system was cleaned with ethyl alcohol (99\%) and ethyl acetate before experimenting with high-viscosity oil POEA-220. Subsequently, the test section assembly was horizontally installed in the evaporator vessel followed by the leakage test with nitrogen at an absolute pressure of $800 \mathrm{kPa}$ for $24 \mathrm{~h}$ to ensure an airtight experimental system. Then, with the help of a vacuum pump and digital weight balance, $6.24 \mathrm{~kg}$ of pure refrigerant R-1234ze(E) was charged into the evaporator vessel.

The test was conducted with pure refrigerant R-1234ze(E). Subsequently, high-viscosity oil POEA-220 was added to the pure refrigerant via gear pump and digital weight balance by the mass fraction of $0.25,0.5,1,2,3,5$ and $10 \%$. The refrigerant level was monitored at regular intervals to ensure a negligible refrigerant loss. All the pool boiling data were measured by decreasing heat flux to minimize the hysteresis effect. MX-100 data logger and the personal computer were used to record the data for further analysis.

\section{Results and Discussion}

\subsection{Effect of Surface Aging on HTCs Curve with Pure Refrigerant}

The nucleate pool boiling experiments were performed with low-GWP refrigerant R$1234 z e(E)$. Figure 3 plots the measured heat transfer coefficients (HTCs) versus the applied heat flux $\left(10 \mathrm{~kW} / \mathrm{m}^{2}\right.$ to $\left.90 \mathrm{~kW} / \mathrm{m}^{2}\right)$ for the initial surface and aging surface) at different saturation temperatures. The solid connected lines represent thr initial surface data, which were taken from the previous study [13], and the dashed conned line represents the present aging surface data. Measurements of the aging surface data were performed nearly 4 months later on the same surface and in the same apparatus. During that period, several other tests were conducted on the same surface, and the system was run for approximately $700 \mathrm{~h}$. However, to collect the present data, the test surface was cleaned with ethyl alcohol and ethyl acetate before the installation in the test apparatus. 


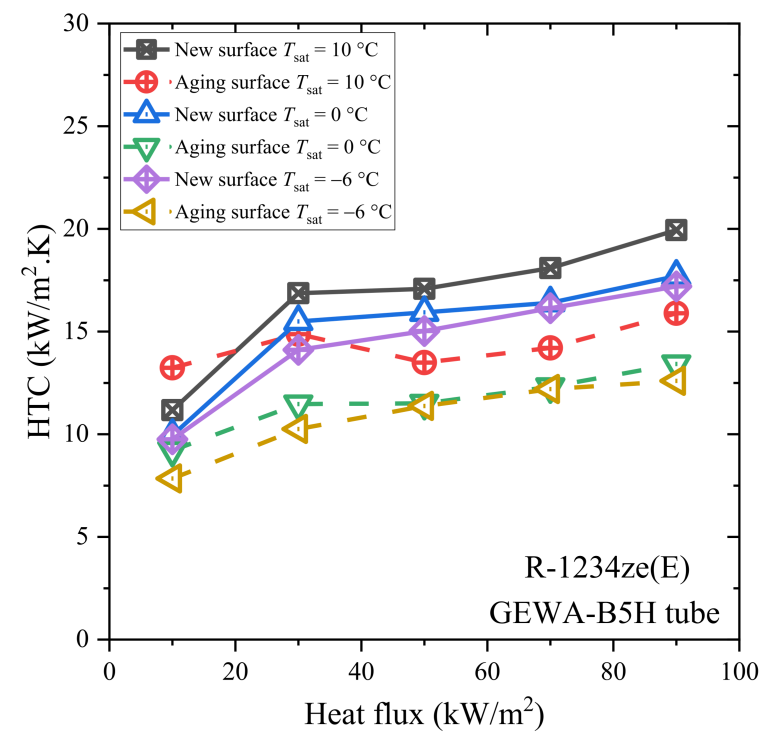

Figure 3. HTCs versus heat flux curves for new surface and aging surface.

From Figure 3, it is clear that HTC's data for the initial surface and the aging surface differ substantially in the high flux-region, but agree closely at low heat flux. This is because after a long period of operation, the surface condition changed, as shown in Figure $4 \mathrm{~b}$. In addition, some of the cavity/channels were blocked. Apparently, many nucleation sites for the aging surface were either damaged or eliminated. As a result, the heat transfer performance deteriorated compared to the new surface. A comparison between the new surface and aging surface is shown in Figure $4 a, b$, respectively. For the aged surface, similar phenomenon have been observed by Kedzierski [18] and Marto and Lepere [19].

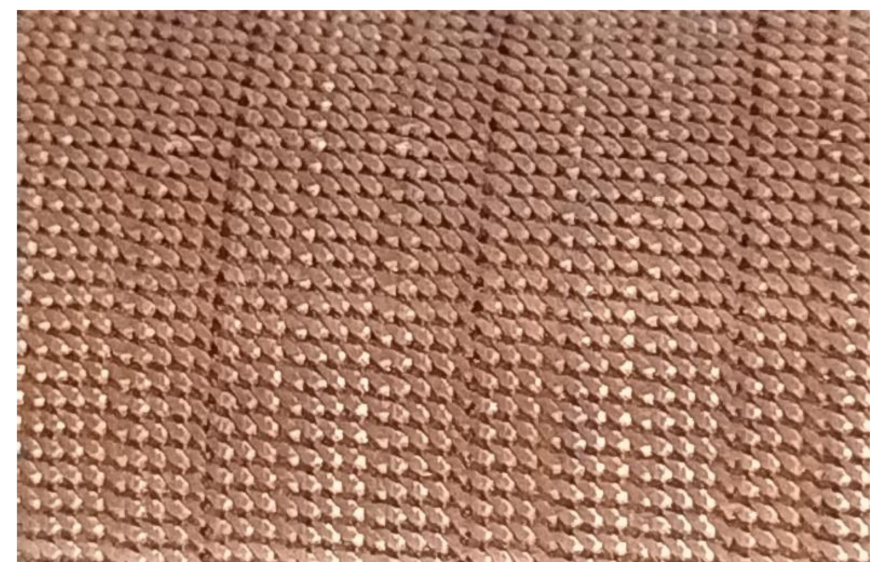

(a) New surface.

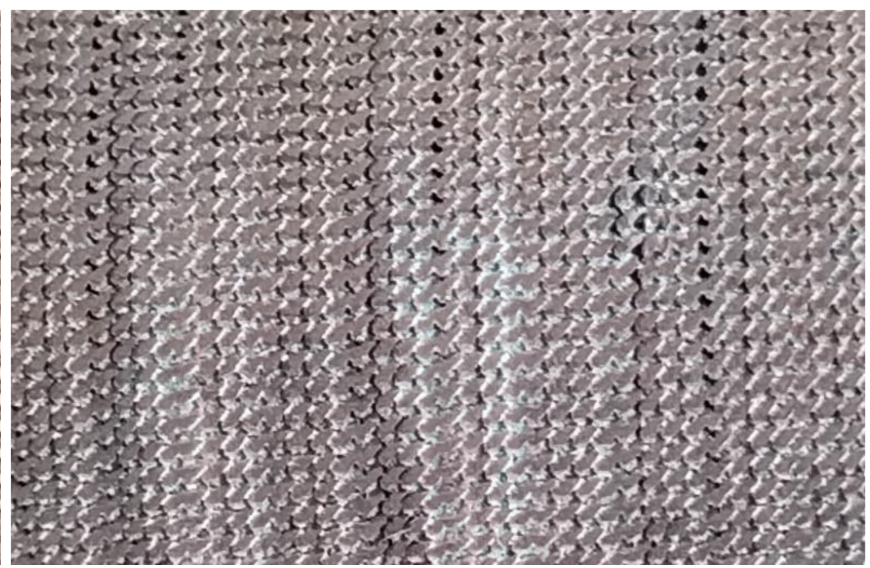

(b) Aging surface (after the experiment).

Figure 4. Comparison between (a) new GEWA-B5H surface and (b) aging GEWA-B5H surface.

\subsection{Influence of High-Viscosity Oil POE-220 (220 cSt) on the HTC Characteristics}

In this section, the heat transfer performance of the refrigerant-oil mixture (R-1234ze/ POEA-220) is presented at the saturation temperatures of $10{ }^{\circ} \mathrm{C}, 0{ }^{\circ} \mathrm{C}$, and $-6{ }^{\circ} \mathrm{C}$. The mass fraction of high-viscosity polyol ester oil POEA-220 varied from 0.25 to $10 \%$, and seven different mixtures were tested on the aging surface. In addition, the present data of R-1234ze(E)/POEA-220 mixtures were compared with R-1234ze(E)/POEA-68 mixtures data [13] and demonstrated in Figures $5-7$ at the saturation temperature of $10{ }^{\circ} \mathrm{C}, 0{ }^{\circ} \mathrm{C}$, and $-6^{\circ} \mathrm{C}$, respectively. Figure 5a plots the measured HTCs versus heat flux for all the mass fractions of high-viscosity oil $(\omega=0.25-10 \%)$ at a saturation temperature of $10{ }^{\circ} \mathrm{C}$. From Figure 5a, it is evident that the addition of high-viscosity oil (POEA-220) $\omega=0.25 \%$ 
to $10 \%$ to the pure refrigerant at a low heat flux region $\left(10 \mathrm{~kW} / \mathrm{m}^{2}\right.$ to $\left.30 \mathrm{~kW} / \mathrm{m}^{2}\right)$ impaired the HTC by $15-21 \%$ compared to the pure refrigerant. Figure $5 \mathrm{~b}$ demonstrates that the addition of low-viscosity oil (POEA-68) $\omega=0.28$ to $5 \%$ deteriorated the HTC by $3-30 \%$ compared to the pure refrigerant. For the R-1234ze(E)/POEA-220 mixtures, with the further increase of heat flux, an enhancement between $30 \mathrm{~kW} / \mathrm{m}^{2}$ and $70 \mathrm{~kW} / \mathrm{m}^{2}$ in the HTC over the pure refrigerant prevailed for all the mass fractions of oil except $\omega=10 \%$. At a high heat flux $90 \mathrm{~kW} / \mathrm{m}^{2}$, the high mass fraction of oil $\omega=5$ and $10 \%$ impaired the HTC by $5-53 \%$ compared to the pure refrigerant. The average degradation in the HTC compared to the pure refrigerant for $\omega=10 \%$ was $29 \%$. On the other hand, Figure $5 \mathrm{~b}$ shows that enhancement in the HTC over the pure refrigerant was only for the low mass fraction of oil $\omega=0.28 \%$ and $0.5 \%$ in the high heat flux region between $30 \mathrm{~kW} / \mathrm{m}^{2}$ and $90 \mathrm{~kW} / \mathrm{m}^{2}$. Further, an increase in the mass fraction of oil $\omega=1$ to $5 \%$ deteriorated the HTC when compared to the pure refrigerant.

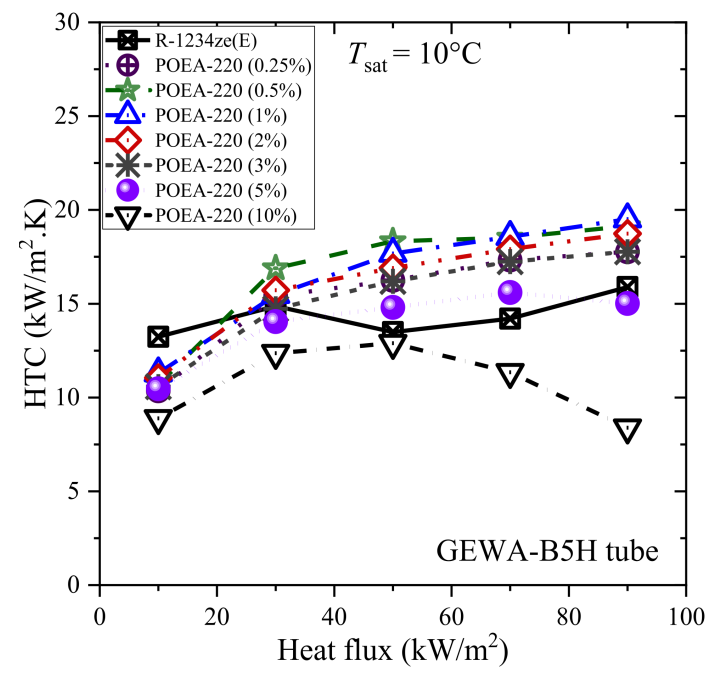

(a) R-1234ze(E)/POEA-220 mixture versus $q^{\prime \prime}$.

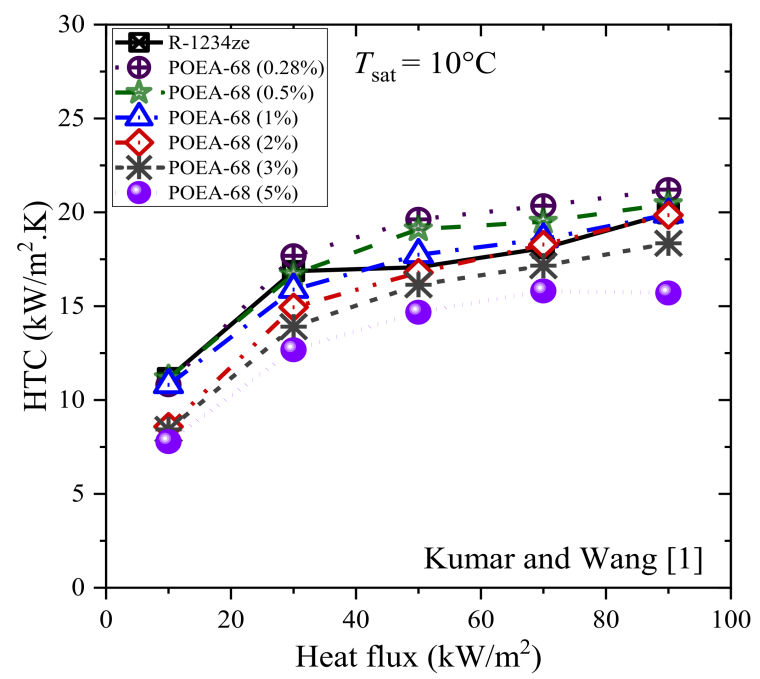

(b) R-1234ze(E)/POEA-68 mixture versus $q "$.

Figure 5. HTC versus $q^{\prime \prime}$. (a) R-1234ze(E)/POEA-220 mixture (b) R-1234ze(E)/POEA-68 mixture at $10^{\circ} \mathrm{C}$.

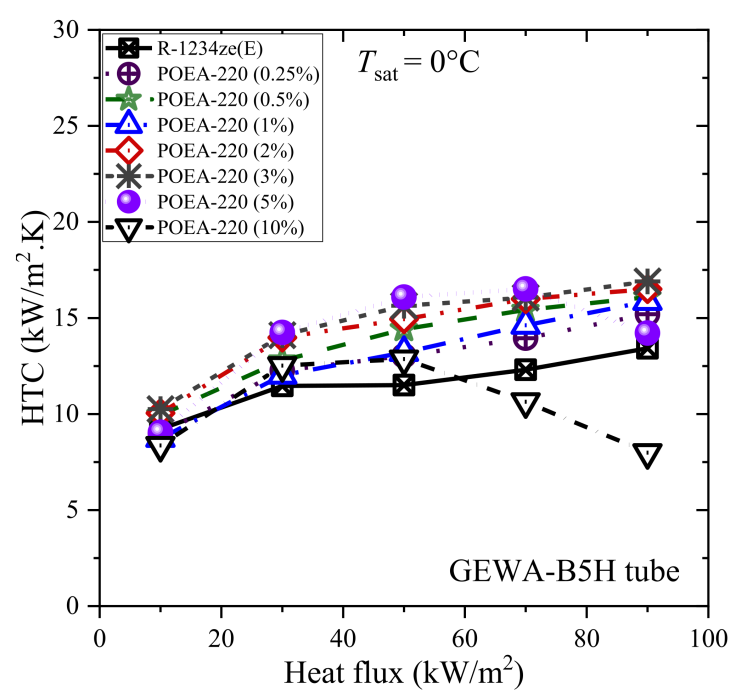

(a) R-1234ze(E)/POEA-220 mixture versus $q "$.

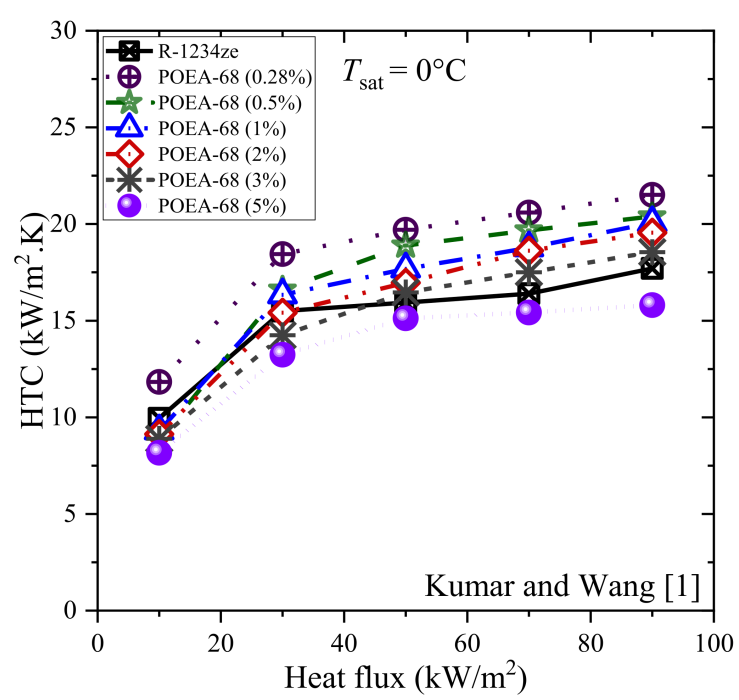

(b) R-1234ze(E)/POEA-68 mixture versus $q "$.

Figure 6. HTC versus $q^{\prime \prime}$ (a) R-1234ze(E)/POEA-220 mixture (b) R-1234ze(E)/POEA-68 mixture $0^{\circ} \mathrm{C}$. 


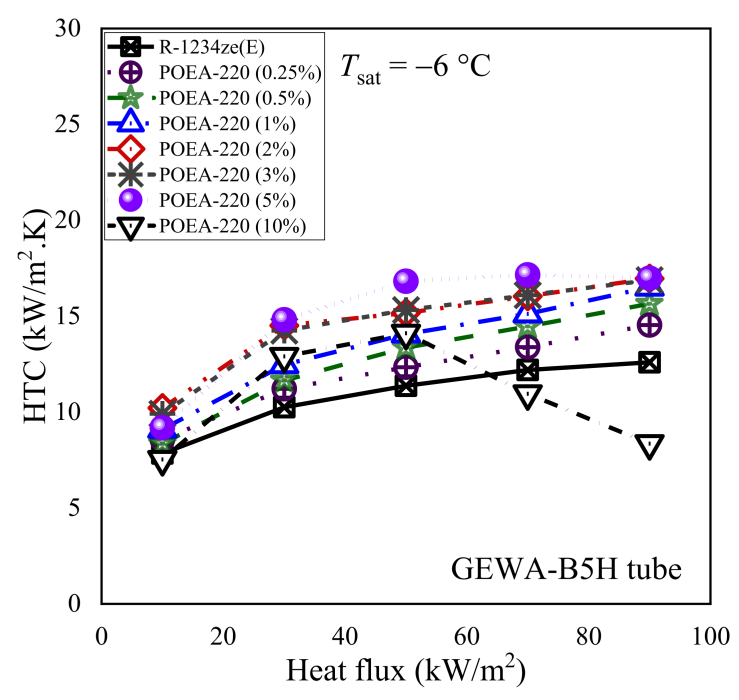

(a) R-1234ze(E)/POEA-220 mixture versus $q^{\prime \prime}$.

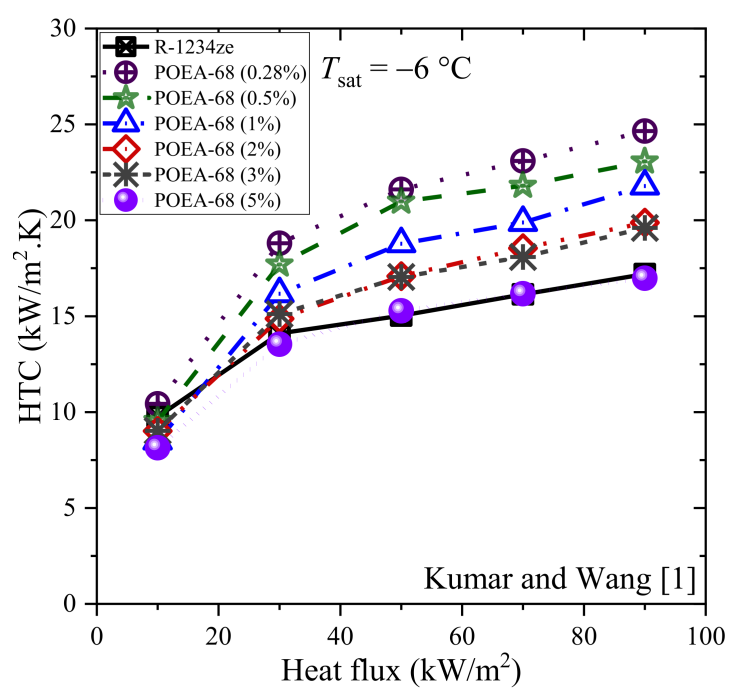

(b) R-1234ze(E)/POEA-68 mixture versus $q^{\prime \prime}$.

Figure 7. HTC versus $q^{\prime \prime}$ (a) R-1234ze(E)/POEA-220 (b) R-1234ze(E)/POEA-68 oil at $-6^{\circ} \mathrm{C}$.

To investigate the influence of saturation temperature on the heat transfer performance of the refrigerant-oil mixtures, tests were further conducted at saturation temperatures of $0{ }^{\circ} \mathrm{C}$ and $-6{ }^{\circ} \mathrm{C}$. The HTC versus heat flux curve for the R-1234ze(E)/POEA-220 mixtures and R-1234ze(E)/POEA-68 mixtures at the saturation temperature of $0{ }^{\circ} \mathrm{C}$ is shown in Figure $6 a, b$, respectively. From Figure $6 a$, it is clear that decreasing the saturation temperature augmented the HTC appreciably even at a 10\% mass fraction, which still shows some HTC enhancement compared to the pure refrigerant in certain heat flux regions $\left(20 \mathrm{~kW} / \mathrm{m}^{2}\right.$ to $50 \mathrm{~kW} / \mathrm{m}^{2}$ ). For $\omega=5 \%$, the R-1234ze(E)/POEA-220 mixtures showed the highest enhancement of the HTC, as shown in Figure 6a. Conversely, the same mass fraction of the oil (5\%) R-1234ze(E)/POEA-68 mixture showed the highest degradation in the HTC, as shown in Figure 6b. Moreover, for the R-1234ze(E)/POEA-68 mixture, the highest enhancement in the HTC was obtained with the lowest mass fraction of oil $\omega=0.28 \%$, and the enhancement in the HTC compared to the pure refrigerant decreased with increasing mass fraction of oil. The opposite trend in HTC enhancement (i.e., enhancement in HTC with increasing mass fraction of oil from $\omega=0.25-5 \%$ ) was observed for the R-1234ze(E)/POEA-220 mixtures.

The further decrease in the saturation temperature on the heat transfer performance for the R-1234ze(E)/POEA-220 mixtures and R-1234ze(E)/POEA-68 mixtures is depicted in Figure $7 \mathrm{a}, \mathrm{b}$ at the saturation temperature of $-6{ }^{\circ} \mathrm{C}$. For the R-1234ze(E)/POEA-220 mixtures and R-1234ze(E)/POEA-68 mixtures, the enhancement trend in the HTC was similar to the trend obtained at the saturation temperature of $0{ }^{\circ} \mathrm{C}$. However, the HTC of the refrigerant-oil mixture was comparatively higher than that of pure refrigerant at a saturation temperature of $0^{\circ} \mathrm{C}$, with a further decrease at the saturation temperature of $-6{ }^{\circ} \mathrm{C}$.

\section{Discussion}

From the obtained experimental results as shown in Figures 5-7, either the enhancement or degradation in the HTC for refrigerant-oil mixtures compared to the pure refrigerant was largely affected by the saturation temperature. Moreover, the heat transfer performance of the high-viscosity polyol ester oil POEA-220/R-1234ze(E) mixtures was superior to the low-viscosity oil POEA-68/R-1234ze(E) mixture. This result differs from the results of Jensen and Jackmen [7] and Spindler and Hahne [10] (the influence of highviscosity oil in terms of HTC enhancement/degradation), and is similar to the results of Mohrlok et al. [11] (in terms of saturation temperature). However, the heat transfer performance of high-viscosity oil POEA-200 is still questionable, as it remains unknown whether the high viscosity itself can easily aggregate on the boiling surface and deteriorate the heat transfer. 
The above question can be answered with the thermodynamic/transport properties of the POEA-68 oil and POEA-220 oil, which are listed in Table 1.

Table 1. Thermophysical properties of POE oil at $0{ }^{\circ} \mathrm{C} .(\mathrm{M}=$ Miscible, $\mathrm{CST}=$ Critical solution temperature $)$.

\begin{tabular}{ccccccc}
\hline Lubricant Oil & $\begin{array}{c}\text { Density } \\
\left(\mathbf{k g} / \mathbf{m}^{\mathbf{3}}\right)\end{array}$ & $\begin{array}{c}\text { Thermal } \\
\text { Conductivity } \\
\mathbf{( W / m . K )}\end{array}$ & $\begin{array}{c}\text { Surface } \\
\text { Tension } \\
\mathbf{( N / m )}\end{array}$ & $\begin{array}{c}\text { Kinematic } \\
\text { Viscosity } \\
\mathbf{( m}^{\mathbf{2} / \mathbf{s})}\end{array}$ & $\begin{array}{c}\text { Specific Heat } \\
(\mathbf{J} / \mathbf{k g}-\mathbf{K})\end{array}$ & $\begin{array}{c}\text { CST in } \\
\mathbf{R}-1234 z e(E) @ 20 w t . \% \\
\left({ }^{\circ} \mathbf{C}\right)\end{array}$ \\
\hline POEA-68 & 969 & 0.095 & 32.6 & 0.001213 & 2301 & $<-60(\mathrm{M})$ \\
\hline POEA-220 & 974 & 0.1423 & 32.1 & 0.007641 & 1805 & $<-60(\mathrm{M})$ \\
\hline
\end{tabular}

Table 1 reveals that the surface tension, density, and critical solution temperature (CST) of both oils were nearly the same. It should be noted that the thermal conductivity of the high-viscosity oil POEA-220 was about 50\% higher than that of the low-viscosity oil POEA68. The higher thermal conductivity of POEA-220 oil improved the temperature distribution alongside the oil-rich layer near the boiling surface, thereby enhancing the heat transfer performance. As a result, lower wall superheats were required for the R-1234ze(E)/POEA220 mixtures than the $1234 \mathrm{ze}(\mathrm{E}) / \mathrm{POEA}-68$ mixtures. Hence, the heat transfer performance of the 1234ze(E)/POEA-220 mixtures was superior to the 1234ze(E)/POEA-68 mixtures. Moreover, it is worth mentioning that Kedzierski [9] previously stated, "lubricants with larger viscosities have higher boiling HTC because the thermal boundary layer is thicker". The present study reveals that a thicker boundary layer was supported by the higher thermal conductivity of oil. Furthermore, the experimental results demonstrated that either the enhancement or degradation in the HTC was significantly influenced by the saturation temperature, heat flux, and mass fraction oil. These phenomena can be explained by the boiling mechanism purposed by Kumar and Wang [13].

It is known that for refrigerant-oil mixture, refrigerant is a volatile component, and oil is a nearly nonvolatile component. Hence, the evaporation rate of the refrigerant in the refrigerant-oil mixture at the liquid/vapor interface is controlled by the saturation temperature and applied heat flux. For example, the liquid pressure of the R-1234ze(E) at the saturation temperature of $10^{\circ} \mathrm{C}, 0{ }^{\circ} \mathrm{C}$, and $-6^{\circ} \mathrm{C}$ was $308.4 \mathrm{kPa}, 216.6 \mathrm{kPa}$, and $172.6 \mathrm{kPa}$, respectively. Therefore, at a high liquid pressure and high heat flux, the refrigerant evaporates through the microchannels at a faster rate, and oil accumulates in the cavity /microchannel to impair the HTC when compare to the pure refrigerant. Similarly, for moderate liquid pressure or low liquid pressure, the evaporation rate of the refrigerant and diffusion rate of oil at the liquid/vapor interface become slower. Subsequently, a thin oil-enriched layer forms on the boiling surface. It should be noted that the above mechanism is also controlled and balanced by the applied heat flux.

In addition, the visual observation made by the high-speed camera reveals that the addition of lubricant oil to the pure refrigerant considerably affected the bubble dynamics and number of nucleation sites, as shown in Figure 8. 


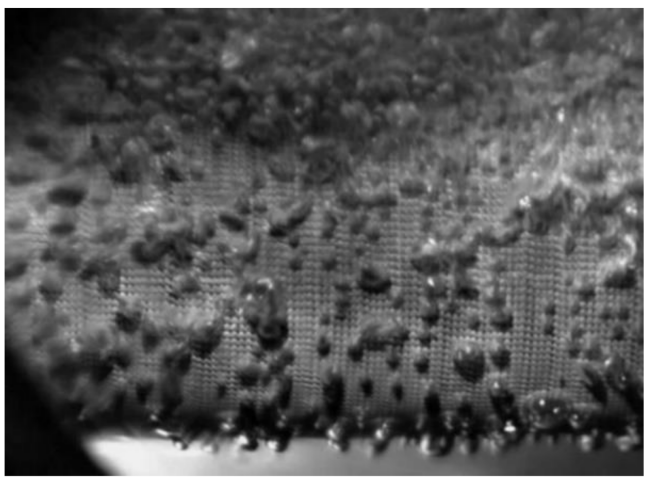

(a) R-1234ze(E), $\omega=0 \%\left(30 \mathrm{~kW} / \mathrm{m}^{2}\right) \quad T_{\text {sat }}=10^{\circ} \mathrm{C}$

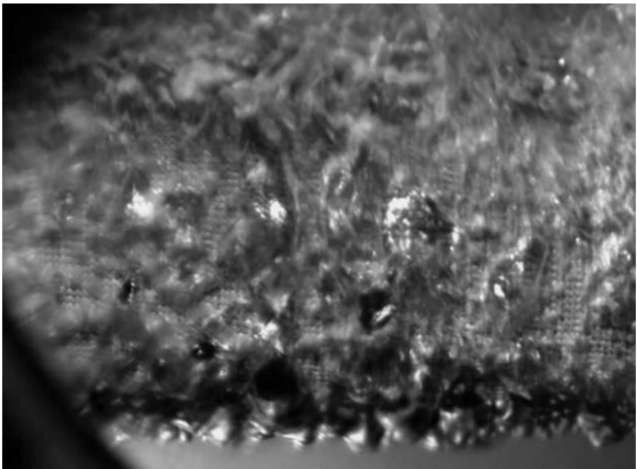

(c) R-1234ze(E), $\quad \omega=0 \%\left(90 \mathrm{~kW} / \mathrm{m}^{2}\right) \quad T_{\text {sat }}=0{ }^{\circ} \mathrm{C}$

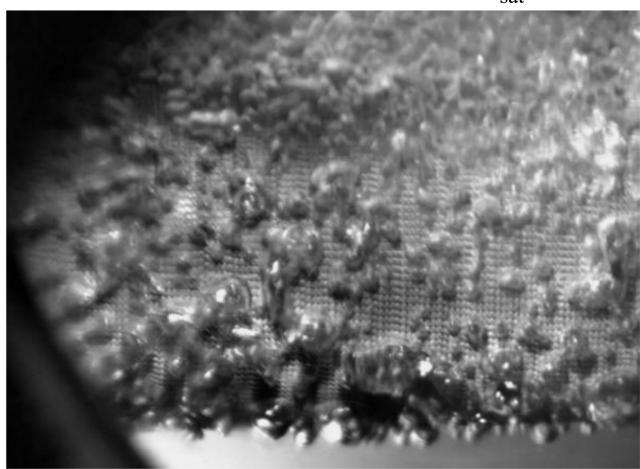

(e) R-1234ze(E), $\omega=0 \%\left(30 \mathrm{~kW} / \mathrm{m}^{2}\right) \quad T_{\text {sat }}=-6{ }^{\circ} \mathrm{C}$

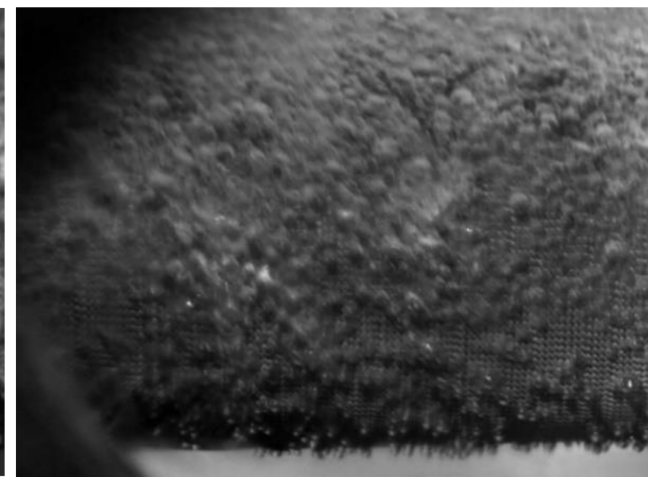

(b) R-1234ze(E), $\omega=3 \%\left(30 \mathrm{~kW} / \mathrm{m}^{2}\right) \quad T_{\text {sat }}=10^{\circ} \mathrm{C}$

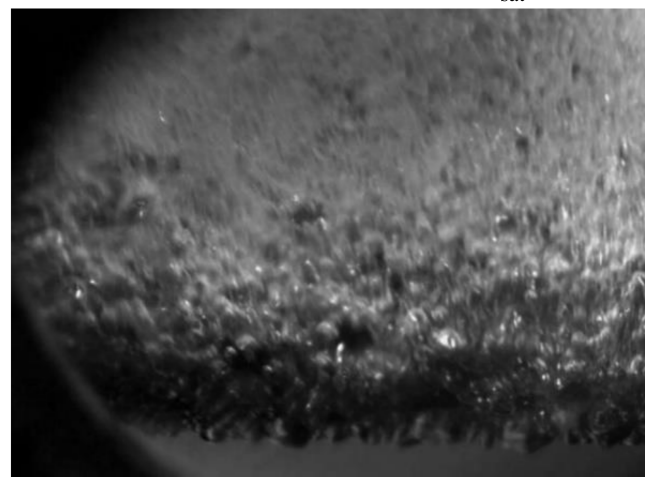

(d) R-1234ze(E), $\quad \omega=10 \%\left(90 \mathrm{~kW} / \mathrm{m}^{2}\right) \quad T_{\text {sat }}=0{ }^{\circ} \mathrm{C}$

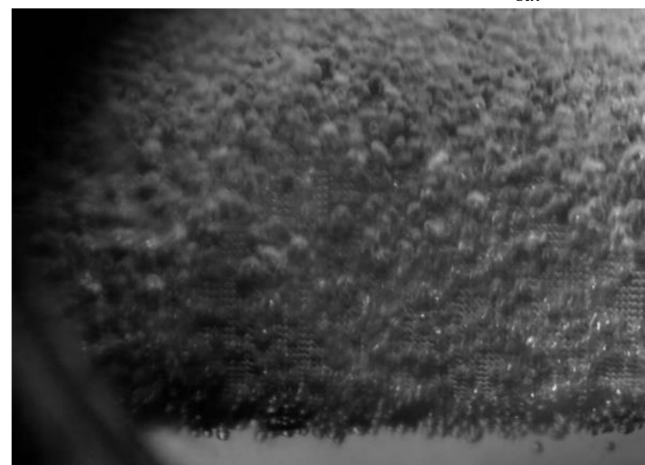

(f) R-1234ze(E), $\quad \omega=5 \%\left(30 \mathrm{~kW} / \mathrm{m}^{2}\right) \quad T_{\text {sat }}=-6{ }^{\circ} \mathrm{C}$

Figure 8. Effect of lubricant oil on bubble size and nucleation sites at different saturation temperatures and heat fluxes.

From Figure 8, it is evident that the addition of lubricant oil to the pure refrigerant decreased the bubble departure diameter and increased the number of nucleation sites. It appears that enhancement in the HTC compared to the pure refrigerant in the presence of oil was associated with a large number of nucleation sites and micro-sized bubbles. On the other hand, the degradation in the HTC was associated with a high mass fraction of oil at a high heat flux (Figure 8d) and occurred due to the formation of the fog of the micro-sized bubble just above the test surface.

\section{Conclusions}

The nucleate pool boiling experiments were performed to investigate the heat transfer performance of the high-viscosity polyol ester oil POEA-220 (220 cSt) with low-GWP refrigerants R-1234ze(E) on GEWA-B5H tube at saturation temperatures of $10{ }^{\circ} \mathrm{C}, 0{ }^{\circ} \mathrm{C}$, $-6{ }^{\circ} \mathrm{C}$. Tests were conducted at heat fluxes ranging from $10 \mathrm{~kW} / \mathrm{m}^{2}$ to $90 \mathrm{~kW} / \mathrm{m}^{2}$, and the obtained results were compared with the previous study [13]. From the present study and the above discussions, the following conclusion can be drawn: 
1. In essence, the HTC of the R-1234ze(E)/POEA-220 mixtures was superior to that of the R-1234ze(E)/POEA-68 mixtures for all the mass fractions of oil (e.g., $\omega=0.25 \%$ to $10 \%)$, especially at low saturation temperatures $\left(0{ }^{\circ} \mathrm{C}\right.$ and $-6{ }^{\circ} \mathrm{C}$.)

2. The higher enhancement in the HTC was observed at lower saturation temperatures, e.g., $0^{\circ} \mathrm{C}$ and $-6^{\circ} \mathrm{C}$ for the refrigerant oil mixtures compared to the pure refrigerant.

3. The bubble dynamics and number of nucleation sites were appreciably affected by the addition of oil to the pure refrigerant.

4. If saturation temperature was below $10^{\circ} \mathrm{C}$, then a mass fraction of the high-viscosity oil POEA-220 of up to $10 \%$ experienced an enhancement in the HTC over the pure refrigerant at heat fluxes ranging from $15 \mathrm{~kW} / \mathrm{m}^{2}$ to $60 \mathrm{~kW} / \mathrm{m}^{2}$.

5. Surface aging reduced the heat transfer performance compared to the new surface.

Author Contributions: Conceptualization, A.K.; experiment, A.K.; investigation, A.K.; writingoriginal draft preparation, A.K.; writing-review and editing, A.K.; supervision, C.-C.W., M.-R.C., J.-H.W., L.-K.S. and K.-S.H. provided administration assistance. All authors have read and agreed to the published version of the manuscript.

Funding: The authors gratefully acknowledge the financial support from the Bureau of Energy of the Ministry of Economic Affairs, and Ministry of Science and Technology of Taiwan under the contracts of MOST 109-2628-E-167-001-MY3.

Data Availability Statement: Not applicable.

Conflicts of Interest: The authors declare no conflict of interest.

\section{References}

1. Bobbo, S.; Nicola, G.D.; Zilio, C.; Brown, J.S.; Fedele, L. Low GWP halocarbon refrigerants: A review of thermophysical properties. Int. J. Refrig. 2018, 90, 181-201. [CrossRef]

2. El-Sayed, A.R.; El Morsi, M.; Mahmoud, N.A. A Review of the Potential Replacements of HCFC/HFCs Using EnvironmentFriendly Refrigerants. Int. J. Air Cond. Refrig. 2018, 26. [CrossRef]

3. Mota-Babiloni, A.; Navarro-Esbrí, J.; Molés, F.; Cervera, Á.B.; Peris, B.; Verdú, G. A review of refrigerant R1234ze(E) recent investigations. Appl. Therm. Eng. 2016, 95, 211-222. [CrossRef]

4. Chen, Y.K.; Hung, J.T.; Tang, H.H.; Tsaih, J.S. POE Lubricant Candidates For Low GWP Refrigerants. In Proceedings of the 16 th International Refrigeration and Air Conditioning Conference, Purdue, West Lafayette, IN, USA, 11-14 July 2016.

5. Jia, X.; Wang, J.; Wang, X.; Hu, Y.; Sun, Y. Phase equilibrium of R1234yf and R1234ze(E) with POE lubricant and thermodynamic performance on the evaporator. Fluid Phase Equilibria 2020, 514, 112562. [CrossRef]

6. Lee, B.-M.; Kwon, J.-W.; Kim, M.-H. Miscibility of POE and PVE oils with low-GWP refrigerant R-1234ze(E). Sci. Technol. Built Environ. 2016, 22, 1263-1269. [CrossRef]

7. Jensen, M.K.; Jackman, D.L. Prediction of Nucleate Pool Boiling Heat Transfer Coefficients of Refrigerant-Oil Mixtures. J. Heat Transf. 1984, 106, 184-190. [CrossRef]

8. Morgan, A.I.; Bromley, L.A.; Wilke, C.R. Effect of Surface Tension on Heat Transfer in Boiling. Ind. Eng. Chem. 1949, 41, 2767-2769. [CrossRef]

9. Kedzierski, M.A. The effect of lubricant concentration, miscibility, and viscosity on R134a pool boiling. Int. J. Refrig. 2001, 24, 348-366. [CrossRef]

10. Spindler, K.; Hahne, E. The Influence of Oil on Nucleate Pool Boiling Heat Transfer. Heat Mass Transf. 2007, 45, 979. [CrossRef]

11. Mohrlok, K.; Spindler, K.; Hahne, E. The Influence of a Low Viscosity Oil on the Pool Boiling Heat Transfer of the Refrigerant R507. Int. J. Refrig. 2001, 24, 25-40. [CrossRef]

12. Kim, N.H.; Kim, D.Y. Pool Boiling of R-123/Oil Mixtures on Enhanced Tubes having Different Pore Sizes. Int. J. Heat Mass Transf. 2010, 53, 2311-2317. [CrossRef]

13. Kumar, A.; Wang, C.-C. Nucleate pool boiling heat transfer of R-1234ze(E) and R-134a on GEWA-B5H and smooth tube with the influence of POE oil. Appl. Therm. Eng. 2022, 201, 117779. [CrossRef]

14. Tatara, R.A.; Payvar, P. Effects of oil on boiling of replacement refrigerants flowing normal to a tube bundle-Part 1: R-123. In Proceedings of the Conference: ASHRAE Transactions, Dallas, TX, USA, 1 July 2000; Volume 106, pp. 777-785.

15. Tatara, R.A.; Payvar, P. Effects of oil on boiling of replacement refrigerants flowing normal to a tube bundle-Part 2: R-134a. In Proceedings of the Conference: ASHRAE Transactions, Dallas, TX, USA, 1 July 2000; Volume 106, pp. 786-791.

16. Kumar, A.; Wang, X.-Z.; Jaya Lakshmi, B.; Hung, J.-T.; Chen, Y.-K.; Wang, C.-C. Nucleate boiling heat transfer of R-134a and R-134a/POE lubricant mixtures on smooth tube. Appl. Therm. Eng. 2021, 185, 116359. [CrossRef]

17. Kumar, A.; Hung, K.-S.; Wang, C.-C. Nucleate Pool Boiling Heat Transfer from High-Flux Tube with Dielectric Fluid HFE-7200. Energies 2020, 13, 2313. [CrossRef] 
18. Kedzierski, M.A. Use of fluorescence to measure the lubricant excess surface density during pool boiling. Int. J. Refrig. 2002, 25, 1110-1122. [CrossRef]

19. Marto, P.J.; Lepere, V.J. Pool Boiling Heat Transfer From Enhanced Surfaces to Dielectric Fluids. J. Heat Transf. 1982, 104, $292-299$. [CrossRef] 